2. Hadziyannis, S.J. 1991. Use of alpha-interferon in the treatment of chronic delta hepatitis. J. Hepatol. 13(Suppl. 1):S21-S26.

3. Wang, K.S., et al. 1986. Structure, sequence and expression of the hepatitis delta $(\delta)$ viral genome. Nature. 323:508-514.

4. Branch, A.D., and Robertson, H.D. 1984. A replication cycle for viroids and other small infectious RNA's. Science. 223:450-455.

5. Rizzetto, M., et al. 1980. Transmission of the hepatitis B virus-associated delta antigen to chimpanzees. J. Infect. Dis. 141:590-602.

6. Gaeta, G.B., Stornaiuolo, G., and Precone, D.F. 2001. Type B and D viral hepatitis: epidemio- logical changes in Southern Europe. Forum (Genova). 11:126-133.

7. He, L.F., et al. 1993. The size of the hepatitis delta agent. J. Med. Virol. 27:31-33.

8. Ryu, W.S., Netter, H.J., Bayer, M., and Taylor, J. 1993. Ribonucleoprotein complexes of hepatitis delta virus. J. Virol. 67:3281-3287.

9. Sharmeen, L., Kuo, M.Y., Dinter-Gottlieb, G., and Taylor, J. 1988. Antigenomic RNA of human hepatitis delta virus can undergo selfcleavage. J. Virol. 62:2674-2679.

10. Casey, J.L., Bergmann, K.F., Brown, T.L., and Gerin, J.L. 1992. Structural requirements for RNA editing in hepatitis delta virus: evidence for a uridine-to-cytidine editing mechanism. Proc Natl. Acad. Sci. U. S. A. 89:7149-7153.

11. Glenn, J.S., Watson, J.A., Havel, C.M., and White, J.M. 1992. Identification of a prenylation site in delta virus large antigen. Science. 256:1331-1333.

12. Bordier, B.B., et al. 2003. In vivo antiviral efficacy of prenylation inhibitors against hepatitis delta virus. J. Clin. Invest. 112:407-414. doi:10.1172/JCI200317704.

13. Schafer, W.R., and Rine, J. 1992. Protein prenylation: genes, enzymes, targets, and functions. Annu. Rev. Genet. 26:209-237.

14. Lau, D.T., et al. 1999. Lamivudine for chronic delta hepatitis. Hepatology. 30:546-549.

\title{
Amyloid $\beta$ and Alzheimer disease therapeutics: the devil may be in the details
}

\section{John R. Cirrito ${ }^{1}$ and David M. Holtzman ${ }^{1,2,3}$}

${ }^{1}$ Department of Neurology,

${ }^{2}$ Department of Molecular Biology and Pharmacology, and

${ }^{3}$ Center for the Study of Nervous System Injury, Washington University

School of Medicine, St. Louis, Missouri, USA

\begin{abstract}
Alzheimer disease $(\mathrm{AD})$ is characterized by the progressive accumulation of amyloid $\beta$ protein $(A \beta)$ in areas of the brain serving cognitive functions such as memory and language. The first of two separate reports (see the related articles beginning on pages 415 and 440) reveals that intrinsic $T$ cell reactivity to the self-antigen $A \beta$ exists in many humans and increases with age. This finding has implications for the design of $A \beta$ vaccines. The second report demonstrates that a number of FDA- approved nonsteroidal anti-inflammatory drugs are capable of lowering $A \beta$ levels in mice. The work suggests that further testing of the therapeutic utility of these types of compounds for the potential treatment of $\mathrm{AD}$ is warranted.
\end{abstract}

J. Clin. Invest. 112:321-323 (2003). doi:10.1172/JCI200319420.

Alzheimer disease $(\mathrm{AD})$ has received a lot of recent attention, particularly in areas related to novel treatments. Recently, the potential therapeutic usefulness of the immune system has become apparent, leading to the question of whether it can be used to directly or indirectly influence ADrelated pathology in beneficial ways.

\footnotetext{
Address correspondence to: David M. Holtzman, Washington University School of Medicine, Department of Neurology, 660 South Euclid Avenue, Box 8111, St. Louis, Missouri 63110, USA. Phone: (314) 747-0286; Fax: (314) 362-2826; E-mail: holtzman@neuro.wustl.edu. Conflict of interest: The authors have declared that no conflict of interest exists. Nonstandard abbreviations used: Alzheimer disease (AD); amyloid $\beta$ protein $(\mathrm{A} \beta)$; amyloid precursor protein (APP); cerebral amyloid angiopathy (CAA).
}

Active immunization with amyloid $\beta$ $(A \beta)$ peptides takes advantage of the immune system to generate antibodies that can somehow decrease $A \beta$ related pathology in mouse models of AD (1). Similarly, passive immunization involves direct administration of anti-A $\beta$ antibodies, bypassing the need for an active immune response $(2,3)$. Since genetic, pathologic, and animal studies suggest that the buildup of $A \beta$ in the brain leads directly or indirectly to cell dysfunction, cell death, and cognitive impairment, increased generation of anti-A $\beta$ antibodies has the potential to prevent or treat $\mathrm{AD}$ by decreasing amyloid burden and its consequences in the brain. Though the first clinical trials for $A \beta$ vaccination were halted due to CNS inflammation in a small sub- set of subjects, active and passive immunization strategies remain a viable potential therapy worth continued exploration. If positive effects can be seen in future trials, it will be important to minimize unwanted toxicity. In this issue of the JCI, Monsonego and colleagues (4) further characterize the innate immune response to $A \beta$ in humans, thus revealing important details about how the elderly body reacts to $A \beta$, and opening new avenues to modify existing vaccination protocols. Also in this issue, Eriksen and colleagues (5) studied traditional NSAIDs that appear to have a nontraditional, COX-independent effect on decreasing $A \beta 42$ production. While these drugs are often used to treat inflammation, they appear to have a novel effect on amyloid precursor protein (APP) cleavage, which is only now becoming apparent and which may be useful in the future as a therapeutic.

\section{A $\beta$-reactive T cells increase with age}

Monsonego et al. (4) found that some healthy, elderly individuals, as well as individuals with $\mathrm{AD}$, contain elevated baseline levels of $A \beta$-reactive $T$ cells. While the general trend is toward a diminished immune response with aging, this demonstrates a selective increase in $\mathrm{A} \beta$-reactive $\mathrm{T}$ cells in older individuals with and without dementia. The reason for this selective expansion of $A \beta$-reactive $T$ cells in elderly individuals remains unclear. It is often presumed that cognitively normal middle-aged and elderly individuals are similar in that they lack AD pathology; however, $A \beta$ deposition in plaques appears to begin about $10-20$ years prior to the onset of even the earliest symptoms sugges- 

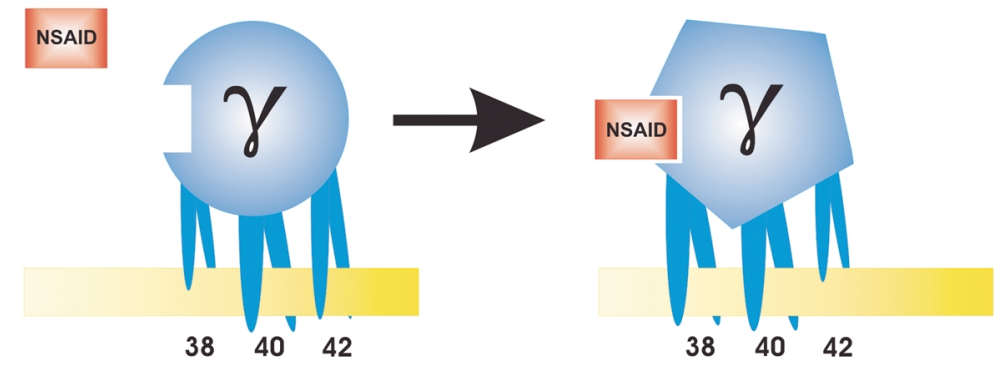

Figure 1

Model of how certain NSAIDs decrease A $\beta 42$ production. NSAIDs may directly bind to the $\gamma$-secretase complex and alter APP processing to decrease $A \beta 42$ production and also change production of other $A \beta$ species.

tive of dementia due to $\mathrm{AD}(6)$. This means that some cognitively normal elderly subjects in this study likely possessed aggregated $A \beta$ deposits in the brain, while it is also likely that most middle-aged individuals (younger than age 50) did not have AD pathology. One interesting possibility is that this change in $\mathrm{T}$ cell population is a response to the presence of $A \beta$ aggregates even in the absence of dementia. The conformation of aggregated $A \beta$ in $\mathrm{AD}$ is predominantly as $\beta$-sheets, whereas the soluble $A \beta$ present in blood and cerebral spinal fluid has little or no $\beta$-sheet structure. Perhaps, this conformational change in endogenous $A \beta$ stimulates a $T$ cell response. Future studies will be necessary to determine if the peripheral $\mathrm{T}$ cell population correlates to CNS pathology or future $\mathrm{AD}$ symptoms (i.e., an antecedent bio-marker).

T cells, $A \beta$, and CNS inflammation While speculative, individuals with elevated $A \beta$-reactive $T$ cells may host a greater immune response to an active immunization with $A \beta$ than someone who lacks this $\mathrm{T}$ cell change. The positive effects of $A \beta$ immunization in mouse models (e.g., decreased plaque burden, behavioral improvement) appear to be mediated by antibodies, not the cellular response (7-10). Thus, augmentation of the production of anti- $\mathrm{A} \beta$ antibodies is likely to be beneficial. However, in the first trial of active $A \beta$ immunization in $\mathrm{AD}$ patients, about $5 \%$ of individuals developed a side effect of CNS inflammation. There is evidence that this complication following active $A \beta$ immunization is due to a $\mathrm{T}$ cell re- sponse (11). It therefore seems logical that minimizing certain aspects of $T$ cell activation would decrease the likelihood of CNS inflammation. Consequently, it may be useful in future vaccination strategies to either exclude subjects that have already demonstrated a substantial $\mathrm{T}$ cell reaction to $A \beta$ or to consider these subjects only for passive immunization. Monsonego and colleagues (4) found that the epitopes for $A \beta$-reactive $T$ cells in humans are primarily amino acids 16-42. Interestingly, however, in studies of active immunization of humans and of mouse models of $\mathrm{AD}$, the primary epitope to which antibodies are generated are amino acids 1-12 $(12,13)$. Because the cellular and humoral immune responses appear to have distinct, dominant epitopes, perhaps an antigen and adjuvant combination can be designed that favor a humoral immune response over a $\mathrm{T}$ cell response.

\section{Certain NSAIDs decrease $A \beta$ production}

Many pathological studies have shown evidence of an inflammatory response (gliosis, increased cytokines) surrounding $\mathrm{A} \beta$ deposits in the $\mathrm{AD}$ brain. It is thought that this response may result in increased neuronal injury, which suggests the possibility that decreasing this response may be beneficial. In light of this, it is of interest that retrospective, epidemiological studies show that NSAID use is associated with a decreased risk of developing AD. Herein, Eriksen and colleagues (5) further define a different molecular mechanism that may be relevant to this relationship. It appears that certain NSAIDs, potentially in a novel, direct interaction with the $\gamma$-secretase complex, can alter APP cleavage and the subsequent species of $A \beta$ produced. Eriksen et al. screened 18 NSAID compounds, including several enantiomers that do not inhibit COX. Interestingly, though structurally similar, these compounds can have different effects on what species of $A \beta$ is produced; some decrease $A \beta 42$, while others decrease $A \beta 40$. The mechanism may be via a direct effect on the $\gamma$-secretase complex, which presumably causes a subtle conformational change and alters APP cleavage (Figure 1). In future studies, it will be important to investigate the molecular details of the NSAID $/ \gamma$-secretase complex interaction. In addition, the drugs most effective in decreasing $A \beta$ levels in humans will need to be determined.

Eriksen and colleagues (5) have focused on decreasing the more aggregation-prone $A \beta 42$ species in order to potentially treat $\mathrm{AD}$. Another potential treatment avenue, however, is to decrease both $A \beta 42$, as well as other species such as $A \beta 40$, the peptide that builds up extensively in cerebral amyloid angiopathy (CAA). If an NSAID compound, or derivative, could be designed to decrease both pathological species of $A \beta$, it may benefit both diseases. While an important aim is to find a drug to decrease $A \beta 42$, it will be important not to increase A $\beta 40$ levels as a consequence. This could potentially lead to increased risk for developing CAA and its consequences such as hemorrhage.

These studies provide exciting new insights and avenues for $\mathrm{AD}$ treatment by suggesting improvements in current vaccination strategies or by furthering our understanding of how NSAIDs alter $A \beta 42$ production. While it is not going to be easy, there remains much hope that the amyloid hypothesis of AD will be tested and that truly effective therapies for AD can be developed.

\footnotetext{
1. Schenk, D., et al. 1999. Immunization with amyloid- $\beta$ attenuates Alzheimer-disease-like pathology in the PDAPP mouse. Nature. 400:173-177.

2. DeMattos, R.B., et al. 2001. Peripheral anti-A beta antibody alters CNS and plasma A beta clearance and decreases brain A beta burden in a mouse model of Alzheimer's disease. Proc. Natl.
} 
Acad. Sci. U. S. A. 98:8850-8855.

3. Bard, F., et al. 2000. Peripherally administered antibodies against amyloid $\beta$-peptide enter the central nervous system and reduce pathology in a mouse model of Alzheimer disease. Nat. Med. 6:916-919.

4. Monsonego, A., et al. 2003. Increased T cell reactivity to amyloid $\beta$ protein in older humans and patients with Alzheimer disease. J. Clin. Invest. 112:415-422. doi:10.1172/JCI200318104.

5. Eriksen, J.L., et al. 2003. NSAIDs and enantiomers of flurbiprofen target $\gamma$-secretase and lower A 342 in vivo. J. Clin. Invest. 112:440-449. doi:10.1172/JCI200318162.
6. Morris, J.C., and Price, A.L. 2001. Pathologic correlates of nondemented aging, mild cognitive impairment, and early-stage Alzheimer's disease. J. Mol. Neurosci. 17:101-118.

7. Morgan, D., et al. 2000. A beta peptide vaccination prevents memory loss in an animal model of Alzheimer's disease. Nature. 408:982-985.

8. Janus, C., et al. 2000. A beta peptide immunization reduces behavioural impairment and plaques in a model of Alzheimer's disease. Nature. 408:979-982.

9. Dodart, J.C., et al. 2002. Immunization reverses memory deficits without reducing brain Abeta burden in Alzheimer's disease model
Nat. Neurosci 5:452-457.

10. Kotilinek, L.A., et al. 2002. Reversible memory loss in a mouse transgenic model of Alzheimer's disease. J. Neurosci. 22:6331-6335.

11. Nicoll, J.A., et al. 2003. Neuropathology of human Alzheimer disease after immunization with amyloid- $\beta$ peptide: a case report. Nat. Med. 9:448-452

12. Town, T., et al. 2001. Characterization of murine immunoglobulin $\mathrm{G}$ antibodies against human amyloid- $\beta 1-42$. Neurosci. Lett. 307:101-104.

13. Hock, C., et al. 2002. Generation of antibodies specific for $\beta$-amyloid by vaccination of patients with Alzheimer disease. Nat. Med. 8:1270-1275

\title{
Endocannabinoids and the regulation of body fat: the smoke is clearing
}

\section{Tamas L. Horvath \\ Department of Obstetrics and Gynecology, and Department of Neurobiology, Yale University School of Medicine, New Haven, Connecticut, USA}

\begin{abstract}
Endocannabinoids, endogenous ligands of cannabinoid receptor type 1 (CB1), have emerged as novel and important regulators of energy homeostasis. A report in this issue (see the related article beginning on page 423) demonstrates reduced body weight, fat mass, and appetite in $\mathrm{CB} 1^{-/-}$ mice. Examination of the underlying mechanisms reveals a dual role for endocannabinoids as they affect both appetite and peripheral lipolysis.
\end{abstract}

J. Clin. Invest. 112:323-326 (2003). doi:10.1172/JCI200319376

Chronically elevated energy expenditure without a corresponding increase in energy intake leads to wasting and death. Almost all species in the wild, and the great majority of the human race, struggle with such negative energy balance in their daily battle for survival. In sharp contrast, however, modern industrialized societies are threatened by the exact opposite: chronically increased energy intake without a respective increase in energy expenditure. This constellation leads to obesity and diabetes as well as a variety of life-threatening consequences of such diseases, such as can-

\footnotetext{
Address correspondence to: Tamas L. Horvath, Department of Obstetrics and Gynecology, and Department of Neurobiology, Yale University School of Medicine, 333 Cedar Street, FMB 339 New Haven, Connecticut 06520, USA. Phone: (203) 785-4597; Fax: (203) 785-4747; E-mail: tamas.horvath@yale.edu.

Conflict of interest: The author has declared that no conflict of interest exists.

Nonstandard abbreviations used: cannabinoid receptor type 1 (CB1); corticotropinreleasing hormone $(\mathrm{CRH})$; cocaineamphetamine-regulated transcript (CART) melanin-concentrating hormone (MCH).
}

cer and cardiovascular diseases $(1,2)$. While it appears intuitively obvious that in the majority of cases, positive energy balance should be corrected by changes in lifestyle and/or diet, the impressive dynamics of the spreading obesity epidemic (3) certainly suggests that, in modern industrialized civilizations, an efficient and safe pharmacological approach to treat obesity would be useful. In light of this, it is not surprising that within the past decades, increasing attention has been paid to central and peripheral regulatory components of energy metabolism to develop pharmacological modulators of appetite and energy expenditure. From this perspective, one of the great, and surprising, discoveries of the past decade was the revelation of an endocannabinoid system and its influences on appetite and metabolism (4-8).

Cannabinoids and endocannabinoids act via $G$ protein-coupled receptors. The strongest effects of endocannabinoids on behavior, including those related to food intake, appear to be mediated by cannabi- noid receptor type 1 (CB1), which is the predominant receptor type in the CNS. The molecular cascade triggered by CB1 activation has been studied in depth (reviewed in ref. 8). In short, the dominant $G$ protein subtypes activated by CB1 belong to the $\mathrm{G}_{\mathrm{i} / \mathrm{o}}$ family; these in turn alter electric properties of membranes, secondmessenger systems, and immediateearly genes. CB1 activation inhibits voltage-gated $\mathrm{L}, \mathrm{N}$, and $\mathrm{P} / \mathrm{Q} \mathrm{Ca}^{2+}$ currents, while activating $K^{+}$currents; and while agonists of CB1 induce the inhibition of adenylyl cyclase, they also induce the activation of focal adhesion kinase and MAPK. CB1associated activation of $\mathrm{G}$ proteins also underlies the stimulation of $\mathrm{NO}$ synthase. Current ideology suggests that the activation or inhibition of CB1 (mainly by fatty acid ethanolamides) influences the aforementioned subcellular events and results in changes in neurotransmitter release at the level of axon terminals (7). However, to date, the phenotype of neurons in the hypothalamic appetite center that are directly affected by cannabinoids has not been elucidated. In this issue of the JCI, a report by Cota et al. (9) greatly advances our understanding of this critical issue by pinpointing those neuropeptide systems in the hypothalamus that most likely mediate cannabinoid-induced changes in energy homeostasis.

\section{Cannabinoids and metabolism}

Anecdotal evidence regarding the robust effect of the recreational drug marijuana (Cannabis sativa) on appetite and food intake has been widely known for centuries (10). However, it was the discovery of marijuana's main psychoactive component, $\Delta^{9}$-tetra- 